\title{
Rip current related drowning deaths and rescues in Australia 2004-2011
}

\author{
B. Brighton ${ }^{1}$, S. Sherker ${ }^{1}$, R. Brander ${ }^{2}$, M. Thompson ${ }^{1}$, and A. Bradstreet ${ }^{1}$ \\ ${ }^{1}$ Surf Life Saving Australia, Locked Bag 1010, Rosebery, NSW 2018, Australia \\ ${ }^{2}$ School of Biological, Earth and Environmental Sciences, The University of New South Wales, Sydney, NSW 2052, Australia
}

Correspondence to: B. Brighton (bbrighton@slsa.asn.au)

Received: 4 December 2012 - Published in Nat. Hazards Earth Syst. Sci. Discuss.: Revised: 15 February 2013 - Accepted: 25 February 2013 - Published: 22 April 2013

\begin{abstract}
Rip currents are a common hazard to beachgoers found on many beaches around the world, but it has proven difficult to accurately quantify the actual number of rip current related drowning deaths in many regions and countries. Consequently, reported estimates of rip current drowning can fluctuate considerably and are often based on anecdotal evidence. This study aims to quantify the incidence of rip current related drowning deaths and rescues in Australia from 2004 to 2011. A retrospective search was undertaken for fatal and non-fatal rip-related drowning incidents from Australia's National Coronial Information System (NCIS), Surf Life Saving Australia's (SLSA, 2005-2011) SurfGuard Incident Report Database (IRD), and Media Monitors for the period 1 July 2004 to 30 June 2011. In this time, rip currents were recorded as a factor in 142 fatalities of a total of 613 coastal drowning deaths $(23.2 \%)$, an average of 21 per year. Rip currents were related to $44 \%$ of all beach-related drowning deaths and were involved in $57.4 \%$ of reported major rescues in Australian locations where rips occur. A comparison with international operational statistics over the same time period describes rip-related rescues as $53.7 \%$ of the total rescues in the US, $57.9 \%$ in the UK and $49.4 \%$ in New Zealand. The range $49-58 \%$ is much lower than $80-89 \%$ traditionally cited. The results reported are likely to underestimate the size of the rip current hazard, because we are limited by the completeness of data on rip-related events; however this is the most comprehensive estimate to date. Beach safety practitioners need improved data collection and standardized definitions across organisations. The collection of drowning data using consistent categories and the routine collection of rip current information will allow for more accurate global comparisons.
\end{abstract}

\section{Introduction}

It is well established that rip currents represent a significant hazard to bathers on many beaches around the world (e.g. Klein et al., 2003; Sherker et al., 2008; Gensini and Ashley, 2010; Scott et al., 2009; Brander et al., 2011). These strong, narrow seaward-flowing currents occur on any beach characterised by waves breaking across a wide area and can occur during conditions of both low and high wave energy conditions on many different types of beaches (Short, 2007). There are different types of rip currents (e.g. Dalrymple et al., 2011; Leatherman, 2012), and most are easily capable of carrying unsuspecting and both experienced and inexperienced bathers significant distances offshore. Bathers caught in rip currents often experience panic and exhaustion while fighting the current or attempting to escape it, which unfortunately can lead to drowning (Brander et al., 2011). For this reason rip currents represent the greatest hazard to bathers on many of the world's beaches and are the primary reason for the establishment of lifeguard and lifesaver services in areas where they occur.

However, while we presently have a good scientific understanding of the morphologic behaviour, occurrence and flow dynamics of rip currents (MacMahan et al., 2006; Dalrymple et al., 2011) and our knowledge of the people who get caught in them is improving (Drozdzewski et al., 2012), we simply do not know how many people drown or are rescued in rip currents. This is largely due to a lack of national reporting systems in many countries as well as the logistical difficulties involved in obtaining accurate and reliable incident reports.

It has therefore proven difficult to provide quantitatively reliable estimates of rip current drowning deaths or the amount of surf rescues directly attributable to rips. For 
example, in the United States it is widely reported by the United States Lifesaving Association (USLA) that the annual number of fatalities due to rip currents exceeds 100 (Brewster, 2010) and Lushine et al. (1999) estimated this number to be closer to 150 . However, using an analysis of historical hazard event data, Gensini and Ashley (2010) suggested that on average 35 people die from rip currents each year in the US. The discrepancy in these estimates is significant and, depending on which estimate is reported by the media, may have implications towards the perceived severity of the hazard to the general public, the funding and sponsorship of valuable rip current public education programs, and the provision of lifeguarding services

A similar situation exists in Australia. More than $80 \%$ of the Australia's 22.6 million residents live within $50 \mathrm{~km}$ of the coastline (CSIRO, 2011). Australian beaches are a prime recreational destination for locals, domestic and international tourists alike, receiving tens of millions of visits per year (Blackwell, 2003). Many of these beaches are characterised by the existence of rip currents. Short (2007) estimated that approximately 17500 rip currents occur on $30 \%$ of Australia's 10685 mainland beaches at any given time. Not surprisingly, rip currents also account for a high incidence of drowning deaths and rescues on Australian beaches. Based on a survey of 689 surf rescues done on 124 beaches in New South Wales during the 1989-1991 patrol season, Short and Hogan (1991) estimated that $89 \%$ of rescues were attributed to rip currents, and this value has been widely reported in the rip current literature (Brander et al., 2011; Hatfield et al., 2012; Miloshis and Stephenson, 2011; Sherker et al., 2010). The aim of this paper is to quantify and describe the number and demographics of rip current related drowning deaths and rescues in Australia. A current national estimate of the magnitude of the rip current hazard is necessary for evidence-based safety practice prioritization.

\section{Methods}

A retrospective search was undertaken for fatal and nonfatal drowning incident data obtained from the Australian National Coronial Information System (NCIS), Media Monitors and Surf Life Saving Australia's (SLSA, 2005-2011) SurfGuard Incident Report Database (IRD).

SLSA is Australia's major water safety, drowning prevention, and rescue authority. The organisation provides volunteer lifesaving services from 310 Surf Life Saving Clubs (SLSCs) around the country. Volunteer patrols are usually carried out over weekends and public holidays during extended summer seasons. SLSA also provides a professional lifeguard service, the Australian Lifeguard Service (ALS), to 63 local government areas. ALS lifeguards patrol on both weekends and weekdays during the extended summer period. SLSA lifesavers and ALS lifeguards together perform an average of 13151 rescues per year (SLSA, 2005-2011).
The SurfGuard IRD is a web-based portal used by SLSA services to electronically record incident reports. Reports are required when treatment is administered after an incident such as a carnival incident, minor first aid, major first aid, or major rescues. Reports for search and rescue operations, member injuries, employee injuries, marine stings, and general complaints are also recorded. The reports are regularly uploaded to the SurfGuard database by club, branch, or state personnel.

Media monitor services track and monitor news published in newspapers, magazines, journals, television, radio, internet and social networking sites. Our subscription results in a publication produced bi-monthly that includes media relating to SLSA and Australia's coastal incidents and hazards.

SLSA's National Coastal Safety Report (2011) defines a coastal drowning death as "a fatality arising from the process of respiratory impairment from submersion/immersion in the foreshore, seabed, coastal water, and air space above a large body of water (harbour/bay/inlet), including areas up to 2 nautical miles (NM) offshore and of which the landward boundary is the line of mean high water, except that where that line crosses a river/inlet, the landward boundary at that point shall be the point upstream that is calculated by multiplying the width of the river/inlet mouth by 5". These coastal/inland boundaries have been adopted from New Zealand's Resource Management Amendment Act 1993 (NZ, 1993).

A search query was performed on NCIS for all deaths due to drowning between 1 July 2004 and 30 June 2011. NCIS case files were searched according to mechanism 1 "threat to breathing" and specifically mechanism 2 "drowning or near-drowning". NCIS documents (including coronial findings, autopsy reports, toxicology reports, and police reports) were also searched for inclusion of the following text instances: "drown", "drowning", or "immersion". Incidents were defined as rip current related when witness statements included the cause as a rip current, a strong current taking the deceased out to sea or the individual being swept away from a surf beach. Deaths that were reported as unintentional, unknown intent and unlikely to be known intent were included. Deaths were excluded if they met the following conditions: the cause was reported as intentional; drowning was not the primary cause of death; or drowning occurred at an inland location or more than $2 \mathrm{NM}$ offshore.

Fatal drowning incidents were verified by each State Surf Life Saving Centre, and compiled for analysis by Surf Life Saving Australia's Operations and Research Departments. The following variables were recorded for each fatal drowning incident: state; date; drowning location; GPS coordinates; time; age; gender; incident type; activity information; whether the incident was work-related; whether is was entered into IRD; IRD number; NCIS case number; whether the case is open/closed; whether the case was reported by the state; the original source of information; drowning location suburb; local government area; postcode; associated 
SLS club; month; day; season; quarter; victim's name; address; residence country; residence distance to coastline; residence distance to drowning location; victim's birth country; nationality; time in Australia; main language; additional activity information; the victim's experience in the activity; whether the incident was rip current related; detailed description of the incident; details relating to alcohol, drugs, or health conditions; weather conditions; wind conditions; sea conditions/wave size; wave type; water surface; temperature; tides; distance to a lifeguarding service; whether or not the location was patrolled at the time; personnel who first sighted the incident; first rescued; other services; and resuscitation details.

Non-fatal drowning incidents were compiled from incident reports in the IRD. All incidents categorised as "major rescues" were examined from 1 July 2004 to 30 June 2011. A major rescue is defined by SLSA as a rescue where a person who required assistance was returned to shore (or place of safety) and who without assistance would have drowned or become injured. The variables reported for each incident were as follows: date; location; patient; rip type; incident type; contributing factors; incident description; and nature of injury.

Incidents were considered rip current related if the incident reports included the following: (i) an associated "rip type" as "permanent", "fixed", "travelling", or "flash"; or the option "rip type" within the "contributing factors" category; or (ii) the "incident description" included the patient being caught in a rip current. Descriptions included text such as "swept/washed offshore/out to sea", "struggling in currents unable to return to shore", or "caught in strong current" (except where incident was at a river mouth or creek). Major rescues that were land-based (i.e. caught in tree, impaled on land, vehicular accidents) were also excluded from the analysis.

In order to compare Australian SLSA results with those overseas, operational statistics from 2004 to 2011 were obtained via personal request from the United States Lifesaving Association (USLA), the United Kingdom Royal National Lifeboat Institute (RNLI), and Surf Life Saving New Zealand (SLSNZ). The USLA data describe the "total rescues" and "rip" rescues for each year. RNLI data are described as "total water assists" and "with rip current as a factor". SLSNZ data are described as "number of rescues" and "rip identified as a factor".

\section{Results}

\subsection{Fatalities}

Overall, there were 613 coastal drowning deaths recorded from 1 July 2004 to 30 June 2011 in Australia. Of these, rip currents were a confirmed factor in 142 of the drowning deaths (23.2\%, 0.10 per 100000 pop., Fig. 1) ascertained

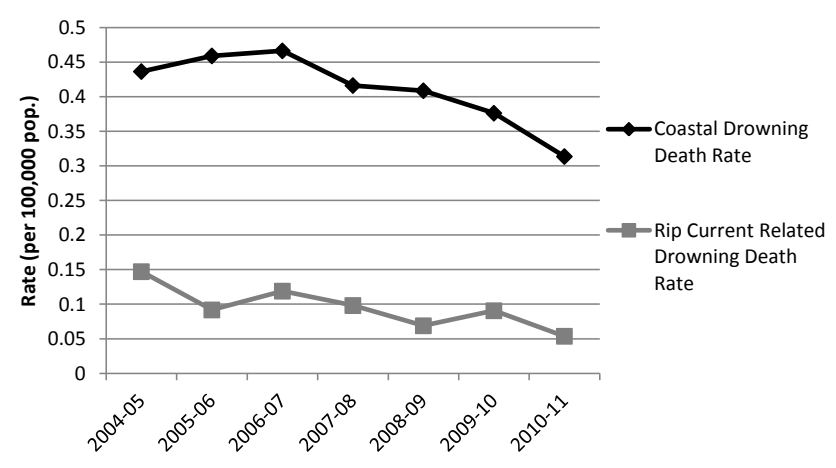

Fig. 1. Coastal drowning death rates and those that are related to rip currents in Australia from 2004-2011.

from the incident report descriptions. As shown in Fig. 2a, the number of annual rip current drowning deaths varied from 12-30 over the seven-year period with an average of 21 rip current related deaths per year. The percentage of drowning deaths attributed to rip currents also varied from 17-34\% with an average of $23 \%$. Of note, there appears to be a decreasing trend in the number of rip current drowning deaths in this period. However, as rip currents are primarily a beachrelated phenomenon, it is also useful to examine the relative proportion of beach-related drowning caused by rip currents. Of the 613 coastal drowning deaths, $293(48 \%)$ were coded as occurring at a beach location. Out of the 142 rip current related deaths, 130 were coded as occurring at a beach location. This suggests that at least $44 \%$ of all beach drowning deaths are attributable to rip currents.

Of the 142 coastal drowning deaths attributed to rip currents, the majority were associated with swimming/wading $(107 ; 75.4 \%)$ followed by attempting a rescue (20; $14.1 \%)$, watercraft use $(9,6.3 \%)$, and other activities $(6$, $4.1 \%$ ) (Fig. 3a). "Other" activities include rock/cliff-related other than fishing, rock fishing, and scuba diving. Watercraft activities include the use of non-powered craft such as surf and boogie boards. Performing activities such as fishing or diving around rocky headlands also resulted in rip current exposure. The age groups most represented in rip-related fatalities were $20-24(18 ; 12.7 \%), 25-29(20 ; 14.1 \%)$, and 30$34(17 ; 12.0 \%)$. Males were involved in $120(84.5 \%)$ incidents and females were involved in $22(15.5 \%)$ (Fig. 4a).

New South Wales has the highest number of rip current related drowning deaths in Australia with 70; this is $28.6 \%$ of the coastal drowning deaths in the state. This is followed by Queensland $(28,28.3 \%)$, Victoria $(17,18.9 \%)$, South Australia (12, $23.5 \%)$, Western Australia (8, 9.9\%), Tasmania $(6,16.7 \%)$ and the Northern Territory $(1,9.1 \%)$. There is no reliable denominator to report coastal drowning deaths as a rate. 

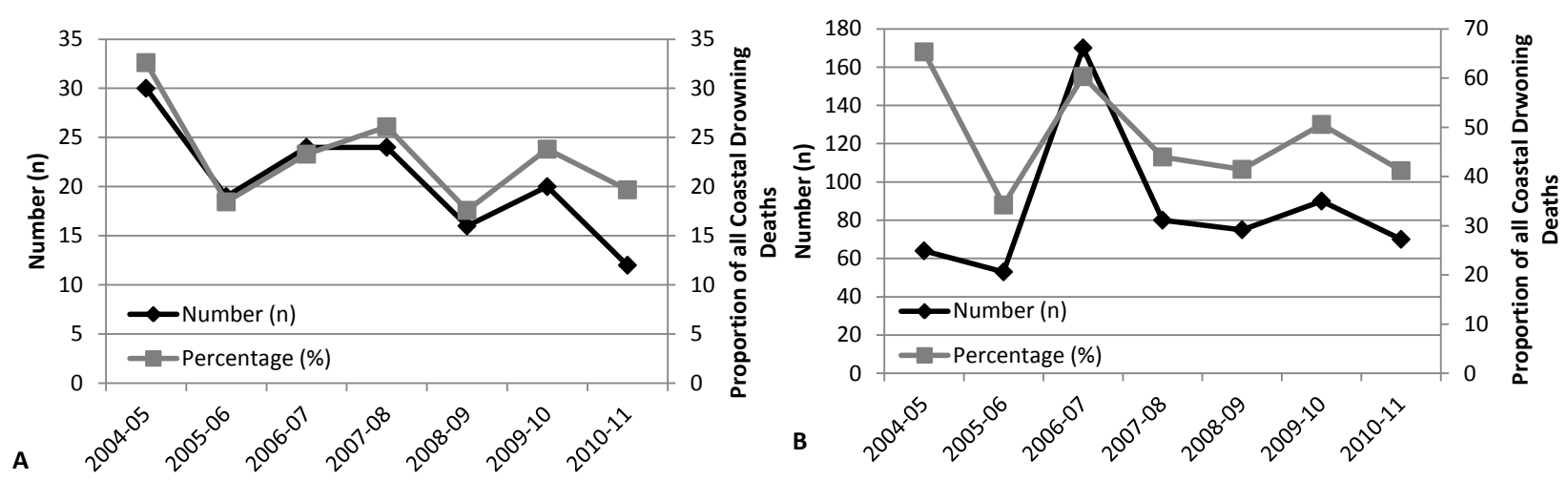

Fig. 2. (A) Rip-related drowning deaths in Australia from 2004-2005 to 2010-2011 ( $n=142)$ and (B) rip-related major rescues in Australia from 2004-2011 $(n=602)$.

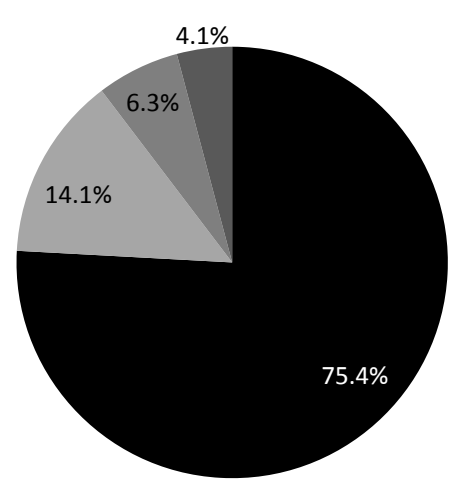

A

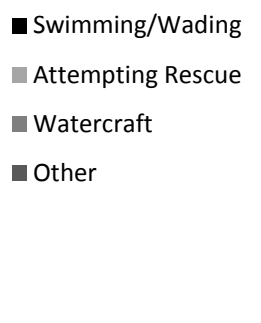

- Swimming/Wading

- Attempting Rescue

- Watercraft

- Other

$\sqrt{2}+2$

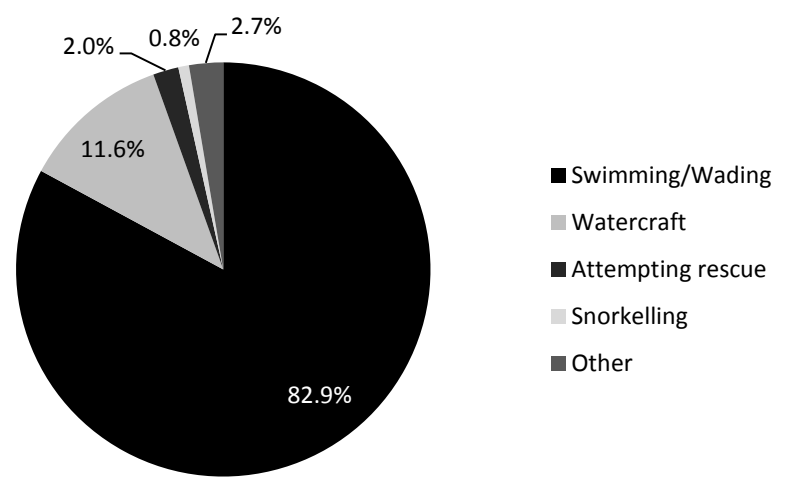

B

Fig. 3. (A) Activities related to rip-related drowning deaths in Australia 2004-2011 ( $n=142)$, and (B) activities related to rip current rescues in Australia 2004-2011 $(n=602)$.

\subsection{Major rescues}

SLSA volunteer lifesavers and ALS lifeguard services performed a total of 92058 rescues (average 13151 per year) during the patrol seasons from 2004 to 2011. The vast majority of these were simply logged as a "rescue" without information given relating to the actual cause, so the amount of total rescues directly related to rip currents is impossible to ascertain. Therefore, this study focussed on the number of "major rescue" incidents which made up $1.4 \%$ (1246 rescues) of the reported total. Of these "major rescue" events, $602(48.3 \%)$ were recorded as related to rip currents. As shown in Fig. 2b, between 2004 and 2011 the number of rip current related major rescues ranged from 53170 and the percentage from $34-65 \%$. On average, there were $86(48 \%)$ rip current related major rescues per year.

Of the 602 major rescues attributed to rip currents, the dominant associated activity of the individuals involved was swimming/wading $(499 ; 82.9 \%)$. This was followed by watercraft use $(70 ; 11.6 \%)$, attempting a rescue $(12,2.0 \%)$, snorkelling $(5,0.8 \%)$, and other $(16,2.7 \%)$. "Other" activi- ties include rock/cliff-related other than fishing, rock fishing, and scuba diving (Fig. 3b).

The age group most represented in rip-related major rescues was the $15-19(90 ; 15 \%)$ age bracket. This was followed by $10-14(75,12.5 \%)$ and $20-24(44,7.3 \%)$. There were $224(37.3 \%)$ incidents where age was not recorded. Males were involved in at least $294(48.8 \%)$ incidents and females were involved in at least $156(26.0 \%)$. There were 152 $(25.3 \%)$ incidents where gender was not recorded (Fig. 4b).

\subsection{Other reasons for major rescues on surf beaches}

Major rescues that were described to be at a location other than a surf beach have been removed for this analysis $(n=198)$, because the locations are unaffected by rip currents. These included those that occurred in lagoons or rock pools $(n=89)$, boating incidents offshore or at a bar crossing $(n=81)$, as a result of aircraft, hang glider, skydiving, kite surfer or wind surfer malfunction $(n=18)$, or in river/creek locations $(n=10)$. The proportion of rip-related rescues increased from $48.3 \%$ to $57.4 \%$ when these major rescues known to be in areas unaffected by rips are removed. 


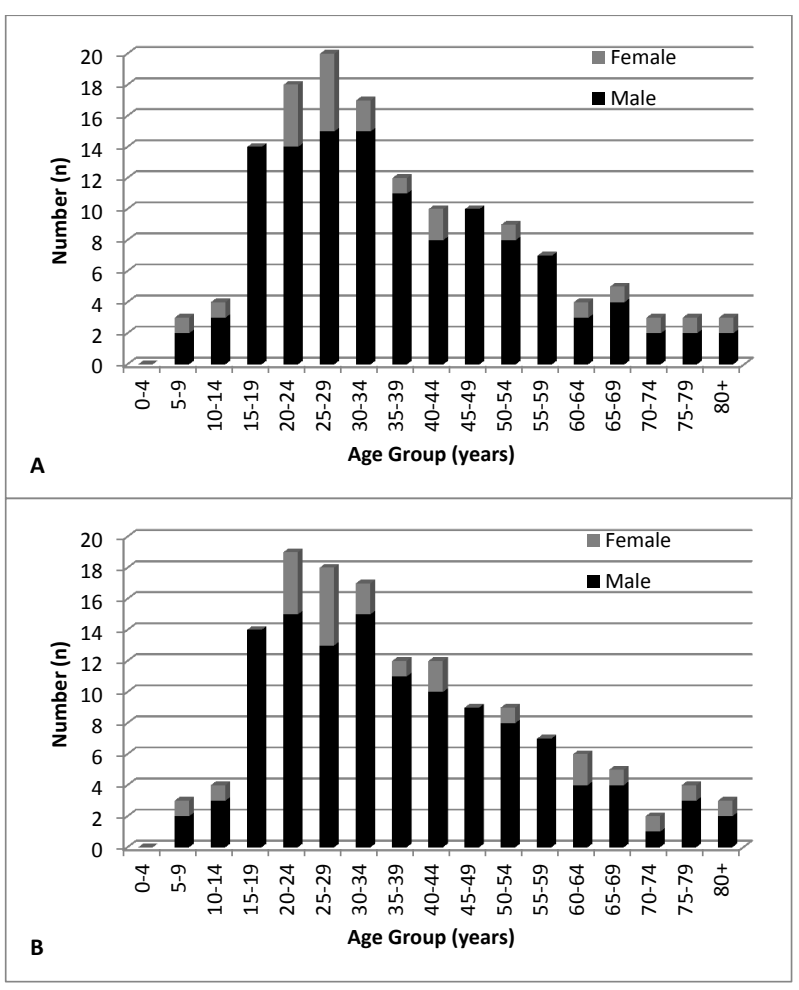

Fig. 4. (A) Age group and gender of rip-related drowning deaths in Australia 2004-2011 ( $n=142)$ and (B) age group and gender of rip-related rescues in Australia 2004-2011 $(n=367) .{ }^{*}$ Incidents of unknown age or gender are not reported here.

The most common hazards reported associated with surf beach major rescues in Australia $(n=1048)$ were rip currents $(602,57.4 \%)$, inexperience/finding oneself out of depth/unable to return to shore unassisted $(153,14.6 \%)$, related to rock/cliff locations $(56,5.3 \%)$, dumping waves (52, $5.0 \%)$, shore break/wave action/tides $(37,3.5 \%)$, medical/collapse $(32,3.1 \%)$, or snorkelling/diving $(20,1.9 \%)$ (Fig. 5).

\subsection{International statistics}

United States Lifesaving Association (USLA) operational statistics from 2005 to 2011 reported a total of 220723 riprelated rescues, an average of 31532 per year (USLA, 2011). This total represents $53.7 \%$ of the total rescues during this time. The Royal National Lifeboat Institution (RNLI) reported 6153, an average of 879 per year, or $57.9 \%$ of the total water assists in the United Kingdom (RNLI, 2011). Surf Life Saving New Zealand (SLSNZ) reported a total of 5597 riprelated rescues, an average of 800 per year, or $49.4 \%$ of the total rescues. Surf Life Saving Australia (SLSA, 2005-2011) IRD reports included 602 rip-related "major rescues", an average of 86 per year, which represents $48.3 \%$ of all of the major rescues recorded during the same time frame (Fig. 6).

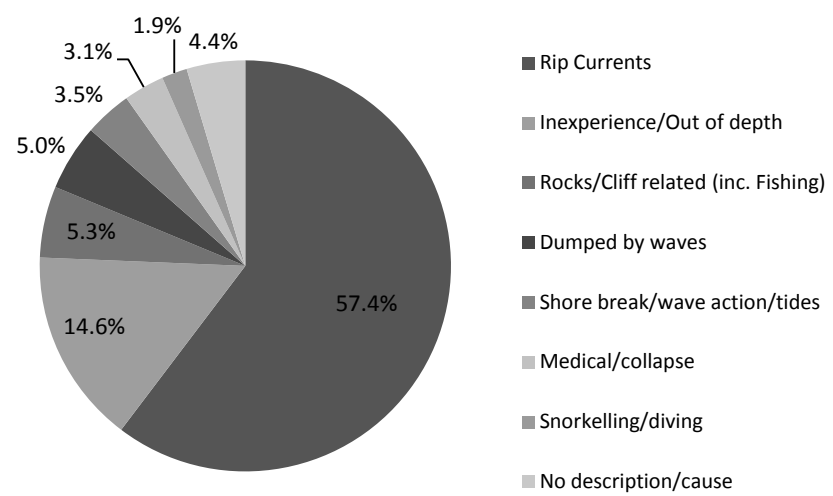

Fig. 5. Causes related to major rescues on surf beaches in Australia 2004-2011 ( $n=1048)$.

\section{Discussion and conclusions}

The findings of this study have important implications for our understanding and reporting of rip current related drowning and rescues in Australia. Many studies on rip currents (e.g. Sherker et al., 2008; Brander and MacMahan, 2011) have suggested that anywhere from 40-60 people drown in rip currents each year in Australia. However, these numbers are largely speculative assumptions and/or based on anecdotal information. This study has shown that the confirmed number of average annual fatalities due to rip currents is 21 , representing on average $23 \%$ and $44 \%$ of all coastal and beach drowning deaths in Australia respectively. A similar scenario applies to the number of rip current related rescues. The study by Short and Hogan (1994) of 689 surf rescues done on 124 beaches in New South Wales between 1989-1991 suggested that $89 \%$ of surf rescues are related to rip currents. Widely quoted in the literature, this estimate no doubt has had an influence on reported anecdotal rip current drowning numbers. However, our results based on "major rescue reports" suggest that rip currents are the cause of $57.4 \%$ of rescues on beaches where they occur. Again, this value is much lower than previously reported, but it is consistent with previously described values reported for the United States, the United Kingdom and New Zealand.

One limitation of this study is the completeness of data on rip current related rescues and fatal drowning deaths. The results reported are likely to underestimate the actual extent of the rip current hazard for a number of reasons. First, it is a significant challenge to identify rip current related incidents within data sets presently available due to the logistical difficulty in obtaining accurate cause of drowning or rescue reports in all cases. For example, we have focussed on the "major rescue reports", which constitute only $1.4 \%$ of the 13151 total rescues reported each year by SLSA, because this is the only database which specifically documents rip currents as a cause of rescue. The vast majority $(98.6 \%)$ of rescues do not result in an incident report, because treatment is unnecessary 


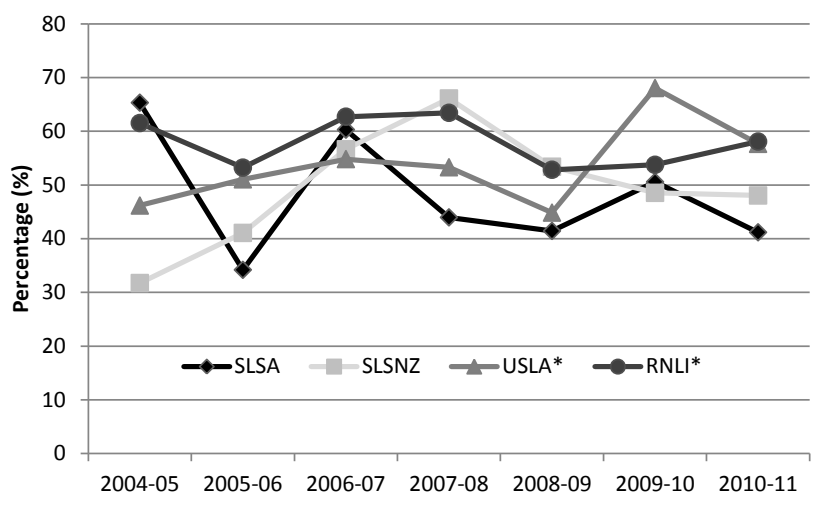

Fig. 6. International rip-related rescues in Australia, New Zealand, the United States, and the United Kingdom. * Note: USLA and RNLI report calendar year data.

and the patient usually walks off unharmed. The rescues that are recorded on incident forms may not include a detailed description or the causation as rip currents. Many major rescues caused by rip currents could have been recorded as "inexperienced/out of depth" based on the lifesavers' perception. In addition, there is no way of knowing how many individuals get caught in rips located in unpatrolled areas when SLS services are not alerted. We know that $83 \%$ of rip current survivors surveyed reported that they were able to escape the rip without any assistance from a lifesaver (Drozdzewski et al., 2012).

A second reason for potential under-estimation of the rip current hazard relates to our use of data from SLSA reports only. There are 15 independent lifeguard services that patrol in Australia and do not contribute incident data to SurfGuard and often lack an accurate or consistent incident database. Third, our data have used proportions based on total number of incidents per year, which include many incidents/rescues recorded by lifesavers that are not necessarily at surf beaches where rips are a factor. For example, we were able to eliminate 198 major rescues from the total of 1246 , because they were known to be in areas unaffected by rip currents. The proportion of rip-related rescues increases from $48.1 \%$ to $57.4 \%$ when these major rescues known to be at locations unaffected by rips are removed.

Finally, Australia has a long and varied coastline having beaches with varying wave, tide and morphological characteristics. Not all of these beaches are characterised by rip currents. A more detailed analysis relating the type of beach to the number and type of beach drowning or rescue would no doubt indicate that certain regions, or types of beaches, yield different results than those presented in this study.

However, irrespective of potential limitations and underestimation, this study is the first to quantitatively describe rip-related incidents in Australia based on accurate data and provides an important starting reference point for future studies. Our results clearly identify rip currents as a significant hazard to the public who use surf beaches for recreation. Beach safety practitioners need improved and collaborative data collection and standardized definitions across organisations. The collection of drowning data using consistent categories and the routine collection of rip current information will allow for more accurate Australian and global comparisons.

Furthermore, calculating drowning rates using populationbased exposure results in under-reporting and therefore an under-estimation of surf beaches as a hazard. Using respondent results from the NSW Population Health Survey, Mitchell et al. (2011) found that drowning rates were higher using population-risk and person-time risk exposures compared to a population-based exposure. In comparison, exposure-adjusted person-time estimates for drowning were 200 times higher than road traffic fatalities in NSW. Exposure data are needed to normalize data sets. Attempts to collect exposure data have been trialled (Morgan et al., 2009), but accurate national beach usage data are currently unavailable. Improvements in both mortality and rescue data descriptions for rip currents specifically are therefore also needed.

It is also important to note that it is possible to mitigate the rip current hazard, and several beach safety educational campaigns have been evaluated with measured success. Hatfield et al. (2012) described a successful rip current safety intervention where members of the public exposed to the intervention demonstrated improvement in intentions to swim away from a calm-looking rip current, ability and confidence in identifying a rip currents, intention never to swim at unpatrolled beaches, and responses to being caught in a rip current, as compared to control members group who did not receive this intervention. A study by Klein et al. (2003) in Brazil demonstrated fatal drowning events were reduced by $80 \%$ after the introduction of electronic (video) and written media (newspapers, leaflets, and signs) related to beach hazards and their identification.

Swimming at patrolled beaches reduces the likelihood of drowning and near-drowning (White and Hyde, 2010). Sherker et al. (2010) found that $36 \%$ of general beachgoers interviewed chose to swim outside of the flagged area. In a survey of rip current survivors specifically, Drozdzeski et al. (2012) found that $73 \%$ of respondents reported they were swimming outside of the flags when caught in the currents. According to SLSA (2011) statistics, $94 \%$ of coastal drowning deaths occur more than $1 \mathrm{~km}$ from patrolled/guarded locations. An emphasis must be placed on educating the public to swim between the flags at patrolled beaches.

Prevention is important. The Australian Water Safety Council has set a goal to reduce all drowning deaths in Australia by $50 \%$ by the year 2020 (AWSC, 2008). As rip-related drowning represents at least $44 \%$ of coastal beach drowning deaths, reducing the risk of rip-related drowning will go a long way to achieving this goal. 
Acknowledgements. The authors would like to acknowledge Chris Brewster of the United States Lifesaving Association, Ross MacLeod of the Royal National Lifeboat Institution, and Brett Sullivan of Surf Life Saving New Zealand for providing operational statistics.

Edited by: I. Didenkulova

Reviewed by: two anonymous referees

\section{References}

Australian Water Safety Council: Australian Water Safety Strategy: Reducing drowning deaths by $50 \%$ by 2020 , AWSC, Sydney, 2008-2011.

Blackwell, B.: The economics of coastal foreshore and beach management: Use, safe bathing facilities, erosion and conservation, PhD Thesis, School of Economics, The Univ. of Qld, 2003.

Brander, R. and MacMahan, J.: Future Challenges for Rip Current Research and Outreach, in: Rip Currents; Beach Safety, Physical Oceanography and Wave Modeling, edited by: Leatherman, S. and Fletemeyer, J., CRC Press, Boca Raton, FL., 1-29, 2011.

Brander, R., Bradstreet, A., Sherker, S., and MacMahan, J.: Responses of swimmers caught in rip currents: Perspectives on mitigating the global rip current hazard, Int. J. Aquat. Res. Edu., 5, 476-482, 2011.

Brewster, B.: Rip current misunderstandings, Nat. Hazards, 55, 161-162, 2010.

CSIRO: Our resilient coastal Australia. http:// www.csiro.au/en/Organisation-Structure/Flagships/

Wealth-from-Oceans-Flagship/ORCA.aspx, last access: 9 October 2012, 2011.

Dalrymple, R., MacMahan, J., Reniers, A., and Nelko, V.: Rip Currents, Annu. Rev. Fluid Mech., 43, 551-581, 2011.

Drozdzewski, D., Shaw, W., Dominey-Howes, D., Brander, R., Walton, T., Gero, A., Sherker, S., Goff, J., and Edwick, B.: Surveying rip current survivors: preliminary insights into the experiences of being caught in rip currents, Nat. Hazards Earth Syst. Sci., 12, 1201-1211, doi:10.5194/nhess-12-1201-2012, 2012.

Gensini, V. and Ashley, W.: An examination of rip current fatalities in the United States, Nat. Hazards, 54, 159-75, 2010.

Hatfield, J., Williamson, A., Sherker, S., Brander, R., and Hayen, A.: Development and evaluation of an intervention to reduce rip current related beach drowning, Accident Anal. Prev., 46, 45-52, 2012.

Klein, A., Santana, C., Diehl, E., and De Menezes, J.: An analysis of hazards associated with sea bathing: Results of five years work in oceanic beaches of Santa Catarina State, southern Brazil, J. Coastal Res., SI 35, 107-116, 2003.

Leatherman, S. P.: Undertow, Rip Current or Riptide, J. Coastal Res., 28, iii-v, 2012.
Lushine, J., Fletemeyer, J., and Dean, R.: Toward a predictive model for rip currents and their impact on public safety with emphasis on physical, demographic, and cultural considerations. Drowning: New Perspectives on Intervention and Prevention, edited by: Fletemeyer, J. and Freas, S., CRC Press, Boca Raton, Fl., 281303, 1999.

MacMahan, J., Thornton, E., and Reniers, A.: Rip current review, Coast. Eng., 53, 191-208, 2006.

Miloshis, W. and Stephenson, W.: Rip current escape strategies: lessons for swimmers and coastal rescue authorities, Nat. Hazards, 59, 823-832, 2011.

Mitchell, R., Williamson, A., and Olivier, J.: Estimates of drowning morbidity and mortality adjusted for exposure risk response, Inj. Prev., 17, 359-360, 2011.

Morgan, D., Ozanne-Smith, J., and Triggs, T.: Direct observation measurement of drowning risk exposure for surf bathers, J. Sci. Med. Sport, 12, 457-462, 2009.

New Zealand Government Resource Management Act, http://www.legislation.govt.nz/act/public/1991/0069/latest/ DLM230265.html, (last access: 9 October 2012), 1991.

Royal National Lifeboat Institution (RNLI) Annual Operational Statistics Report 2011, http://rnli.org/SiteCollectionDocuments/ 2011\%20Operational\%20Statistics\%20Report\%20LR.pdf, (last access: 9 October 2012), 2011.

Scott, T. M., Russell, P. E., Masselink, G., and Wooler, A.: Rip current variability and hazard along a macro-tidal coast, J. Coastal Res., SI 50, 1-6, 2009.

Sherker, S., Brander, R., Finch, C., and Hatfield, J.: Why Australia needs an effective national campaign to reduce coastal drowning, J. Sci. Med. Sport, 11, 81-83, 2008.

Sherker, S., Williamson, A., Hatfield, J., Brander, R., and Hayen, A.: Beachgoers' beliefs and behaviours in relation to beach flags and rip currents, Accident Anal. Prev., 42, 1785-1804, 2010.

Short, A.: Australian Rip Systems-Friend or Foe?, J. Coastal Res., SI 50, 7-11, 2007.

Short, A. and Hogan, C.: A three year study into the circumstances behind surf based rescues, in: NSW Beach Safety Program, Sydney, 19 pp., 1991.

Short, A. and Hogan, C.: Rip currents and beach hazards: Their impact on public safety and implications for coastal management, J. Coastal Res., SI 12, 197-209, 1994.

Surf Life Saving Australia: Annual Report, SLSA, Sydney, Surf Life Saving Australia: National Coastal Safety Report, SLSA, Sydney, 2005-2011.

USLA: United States Lifesaving Association Statistics, http://www. usla.org/?page=STATISTICS, (last access: 9 October 2012), 2011.

White, K. and Hyde, K.: Swimming between the flags: A preliminary exploration of the influences on Australians' intentions to swim between the flags at patrolled beaches, Accident Anal. Prev., 42, 1831-1838, 2010. 